\title{
Information Networks in Amenity Transition Communities: A Comparative Case Study
}

\author{
Jordan W. Smith
}

Published online: 7 August 2013

(C) Springer Science+Business Media New York 2013

\begin{abstract}
Amenity transition, a major socio demographic trend in areas rich in natural resources, is characterized by economic and population growth as a result of retirement inmigration, increased rates of second home ownership, and increases in the number of industries that do not need to be proximate to a specific geographic location. Amenity transition is also characterized by increased intra-community conflict between long-term residents and in-migrants. This research analyzes whether the population growth accompanying amenity transition is associated with variations in the structure and characteristics of intra-community informational networks, as sociological theory would suggest. Methodologically, this is accomplished through a comparative analysis of the structure and characteristics of informational networks in three communities undergoing amenity transition. The analyses suggest population density is not related to either the structure of informational networks or the concentration of trust/distrust within them. When considered in conjunction with previous empirical work, these findings suggest the conflicts associated with amenity transition are more likely to arise because of conflicting value systems and ideologies as opposed to social structural changes in the communities themselves.
\end{abstract}

Keywords Affiliation networks · Bipartite networks ·

Two-mode networks

\section{Introduction}

The Growth of Amenity Transition Communities

For the majority of the $20^{\text {th }}$ century, the economic and social stability of many small communities in America was dependent

J. W. Smith $(\bowtie)$

North Carolina State University, Raleigh, NC, USA

e-mail: jordan_smith@ncsu.edu upon their ability to profit from the development or extraction of local natural resources (England and Brown 2003). The accessibility of natural resources was greater in small cities when compared to urbanized areas, and often resulted in homogenous resource-dependent economies. Economic and social stability in small, resource-dependent communities was often short-lived however, as extractive boom periods were often followed by bust periods after a local resource had been exhausted (Freudenburg 1992). Bust cycles were characterized by severely reduced social and economic well being as well as large rates of outmigration and population decline (Smith et al. 2001). For the last three decades of the last century however, communities rich in natural amenities experienced renewed economic and population growth as a result of retirement in-migration, rapid increases in rates of second home ownership, and new industries that did not need to be geographically tethered to a central location of economic production (Johnson 1999). Between 1970 and 1996, for example, average population growth in amenity rich rural counties was $120 \%$ greater than rural counties lacking amenities such as favorable climates, lakes or rivers, and topographical variation (McGranahan 1999).

The growth of amenity-based communities is not only being experienced in the United States. Small communities in other developed countries such as Australia (Holmes 2002, 2006), the United Kingdom (Wilson 2001, 2006), and Italy (Saraceno, 1994) have also experienced shifts away from traditional land uses and industrial clustering towards more diversified modes of economic production. This pattern of development, which has been termed "rural restructuring" by some scholars (Nelson 2001; Woods 2003) affects not just the population densities and economic activities which occur in small communities, it also affects their patterns of intrapersonal social interaction (Gosnell and Abrams 2011). For example, a substantial amount or research has focused on the differences and conflicts between long-time residents, who are believed to be more concerned with local community planning 
efforts, and short-term residents or in-migrants, who are typically portrayed as having a more transitory orientation, and subsequently are less concerned about local planning efforts (Brunson et al. 1997; Salamon 2003a, 2003b).

\section{Implications of Amenity Transition on Community Planning} Efforts

For community planners, amenity-migration can lead to increased difficulties in coming to consensus on local development issues as in-migrants clash with long-term residents over how the community and its surrounding landscape should be developed (Hurley and Walker 2004; Travis 2007). While community planning efforts might be hampered by conflicting values held between long-term residents and in-migrants, the ability to successfully implement planning efforts may also be impacted by more structural ${ }^{1}$ issues related to large-scale inmigration. Greater population growth in amenity rich communities inherently implies greater population densities that, as sociological theory suggests, leads to two key factors likely to hamper planning efforts. First is a decrease in the concentration of intra-community information exchange and second is an increasing distrust in others and in social institutions.

The decreased concentration of intra-community information exchange refers to community residents no longer having to rely on single outlets, such as weekly community newspapers, church services, or civic organizations to disseminate information about local community issues (Flora and Flora 2008). An in-migration of dissimilar others leads to the introduction of alternative modes of communication that often challenge the dominant modes of information dissemination, namely kinship ties, in small cities (Hofferth and Iceland 1998). Consequently, informational exchange in amenity transition communities is likely to be more decentralized and involve a diverse array of institutions such as civic, religious, educational, and interest groups as well as individuals with whom individuals have less-frequent contact. If this proposition is true, it suggests planning efforts in amenity transition communities are likely to face more structural barriers than those generated by conflicting value systems held between inmigrants and long term residents.

A second factor of decreased trust in social institutions is also likely to influence planning efforts. Recent research has found the level of trust individuals place in others as well as the level of trust they place in social institutions is significantly higher in small rural areas relative to their urban counterparts (Beaudoin and Thorson 2004). A long history of sociological theory suggests that as places become more

\footnotetext{
${ }^{1}$ The word "structural" throughout this article simply refers to the relational nature of all social interactions, whether they be between two individuals, or between and individual and an organization (Entwisle et al. 2007).
}

populous and more diverse, individuals become less likely to establish intimate and trusting reciprocal relationships with others (Durkheim 1933). Consequently, they are more likely to be socially isolated and less willing to cooperate with others. This is, yet again, another structural barrier that might also accompany amenity in-migration.

In this study, I set out to explicitly test whether these two factors, a decrease in the density of informational networks and a decreased level of trust placed in others and social institutions, correlate with amenity in-migration and population density levels in amenity rich communities. I accomplish this through a mixed-methods comparative case study of three small communities located in western North Carolina, USA. First, I provide a deeper review of the relationship between amenity in-migration, population density, and decreased concentrations of informational density. I then follow with a more theoretically informed review about the relationship between population density and trust before explicitly forming the hypotheses to be tested.

\section{Related Literature}

Community and environmental planners realize that the successful formulation of policy, development of plans, and implementation of management approaches, often hinges upon how local residents or stakeholders interact with one another (Freeman 2001; Jacobs 1961). All too often, planners cite breakdowns in communication and information dissemination as key factors limiting their ability to achieve desired objectives (Maier 2001). Planning, after all, is a process that occurs within, and is dependent upon a relational structure of individuals and organizations. Consequently, sociological theory can offer insights into how the actual social structure of communities themselves, and inherently the structure of their information networks, can influence the capabilities of local planning agencies. More dynamically, sociological theory can offer key insights into how the capabilities of planning agencies are likely to change as a result of shifts in the social structure of the communities in which they operate.

\section{Population Density and Patterns of Social Interaction}

A vast amount of sociological theory has been devoted to understanding variations in community structure. The earliest writing on community structure can be traced at least as far back as 500 B.C. (Sorokin 1979). Nearly all theories of social structure are rooted in the assumption that any population larger than a small group consists of individuals connected to one another via some form of social interaction (Simmel 1955). The relational nature of human interaction is integral to the flow of information between individuals, groups, 
communities, and larger aggregations (Granovetter 1973). However, interactions between individuals are not completely random across entire populations. Rather, the frequency and intensity of any individuals' interactions are a function of the number of potential others they are physically proximate to (Wilkinson 1991). As a consequence of this basic assumption, numerous social theorists have conjectured that the characteristics of any community fundamentally rest upon the frequency and quality of interactions among its members.

The German social theorist Ferdinand Toennies presented the first theoretical typology of community structure (1887). Toennies argued the organization of any community could be located on a continuum ranging from the fully communal (gemeinschaft) to the fully individualistic (gesellschaft). Fundamental to Toennies' argument was the belief that communities tended to evolve from being composed of individuals primarily concerned about the community as a whole to individuals principally occupied with personal fulfillment. This evolution occurred as communities transitioned form sparse, rural settlement patterns to more-dense, urban agglomerations. Toennies also conjectured that numerous other community characteristics, aside from communal orientation, changed as populations become more urbanized. Specifically, more urban populations tended to be characterized by more industrial diversification, more variable belief systems, more dispersed social ties, more infrequent social interactions, and a greater need for rules to overcome distrust (Brint 2001).

Once the early typology and conceptualizations laid down by Toennies were adopted in the United States, a long list of research sought to document degrees and consequences of the transition of communities form rural to urban (Wilkinson 1991). A large majority of this research was fueled by the Morrill Act of 1890 which tasked land-grant universities with disseminating information among the geographically dispersed rural areas of the country (Field et al. 2002). For social scientists at the time, what was (and arguably still is) of interest is the arrangement and dispersion of people and activities on the landscape. "Dispersion is of sociological importance because of its presumed effects on the interaction of people" (Wilkinson 1991:52). Despite increased interest among social scientists, nearly all research conducted during this time relied upon descriptive case studies of individual communities (Sanders and Lewis 1976).

In the latter half of the twentieth century, empirical research on the relationship between population density and patterns of social interaction gained more analytical traction, particularly with the introduction and widespread dispersion of the network concept (White et al. 1976). Two notable studies conducted during this time explicitly drew upon Toennies' conceptualizations and can subsequently be used to inform the hypothesis being tested in this research. The first of these studies utilized survey data collected from nearly 2,200 residents of England to examine a hypothesized linear relationship between the population density of individuals' communities of residence and those individuals' number of self-reported friendship/kinship ties (Kasarda and Janowitz 1974). Within this "linear-development" hypothesis, population size and density are exogenous factors believed to influence individual social behavior. Following Toennies, it was believed urbanization would lead to a reduced concentration of informational networks. In other words, the presence of friendship and kinship ties were expected to decline as the probability of developing non-intimate ties increased. The results of this research, however, revealed no relationship between population density/urbanization and the dissolution of friendship and kinship ties. The second notable study, conducted several years later using a larger sample of residents within Great Britain, resurrected the linear-development hypothesis (Sampson 1988). Again, no empirical evidence was found for a positive relationship between population densities and individuals' self-reported friendship/kinship ties.

These previous empirical results seem to suggest Toennies' conceptualization, while commonly assumed, does not accurately reflect reality. Consequently, the formal hypothesis under examination in this study is developed from previous empirical work and postulates no relationship between a community's population density and the density of its residents' informational networks.

Population Density and Trust/Distrust in Informational Sources

Before fully disregarding the utility of Toennies' conceptualization, it is important to note he suggested numerous community characteristics could vary relative to level of urbanization. Toennies suggested that not only did the quantity of social ties vary relative to population densities, but their qualitative components did as well. ${ }^{2}$ The strength of individuals' ties to one another as well as their ties to formal and informal association groups are not solely determined by the frequency of interactions. Rather, the strength of a social tie is defined by a combination of both quantitative (e.g., amount of time, frequency of interaction) and qualitative (e.g., emotional intensity, feelings of reciprocity) measures (Granovetter 1973).

This argument is succinctly stated in the early work of Pahl (1966) who pointed out that attempting to classify entire geographic regions as more communally oriented (gemeinschaft) or more individualistic (gesellschaft) resulted in a gross oversimplification of the heterogeneity of communities and the social relationships that occur within them. Pahl

\footnotetext{
${ }^{2}$ However, Toennies argued that both the quantitative and qualitative dimensions of social ties did not co-vary While several studies support Toennies' argument (e.g., Putnam 1993), consistent and definitive support is lacking (Brint 2001).
} 
noted the population density of an area was much less important than the class and life-style characteristics of specific individuals and groups. There is obviously heterogeneity in the patterns of intra-community social interactions that cannot be accounted for through a simple measure of population density alone. He notes that both gemeinschaft and gesellschaft-type relationships can be found among different groups in the same place. Consequently, it is logical for sociologists to place a greater emphasis on the qualitative and socio-psychological definitions of community, such as identity (Bell, 1992) and trust (Greider et al. 1991).

Arguably the most central qualitative measure defining the social ties within a community is the extent to which others are trusted or distrusted (Coleman 1990). Relative to population density, interpersonal trust has been relatively unstudied. Perhaps this is unsurprising, given examinations of rural to urban variations in the nature of interpersonal relationships has been relegated to the margins of disciplines such as rural sociology (Hofferth and Iceland 1998). What is known, however, suggests that population density is related to the quality of interpersonal ties. Data from an analysis of the 1985 General Social Survey, which is administered to a random sample of Americans, revealed the social networks of residents in non-metropolitan areas of the country are comprised of "more intense", closer, relationships relative to residents living in metropolitan areas 3 (Beggs et al. 1996). Relatedly, empirical evidence suggests feelings of reciprocity (particularly among kinship ties) are stronger among individuals living in rural areas relative to their urban counterparts (Lee et al. 1994). More recent evidence also suggests actual reciprocal behaviors, as opposed to subjective feelings, are also higher among individuals living in more sparsely populated areas (Hofferth and Iceland 1998). While this previous research doesn't explicitly gauge the degree of trust present within individuals' networks, the evidence does suggest relational networks in more rural areas are characterized by higher degrees of trust in others and in organizations. Therefore, the formal hypothesis examined in this study proposes that higher levels of trust will be negatively related to a community's population density. The reciprocal is also hypothesized.

\section{Methods}

\section{Comparative Case Studies}

To answer the research questions posed above, I employed a comparative multiple case-study design wherein specific cases (i.e., communities) were selected based upon several key

\footnotetext{
$\overline{3}$ This measure of intensity is constructed from individuals' responses to questions about whether people in their network are "especially close", "somewhat close", or "total strangers" (Marsden 1987).
}

characteristics. First, each community had to have been economically dependent upon natural resource based industries within the past half-century. ${ }^{4}$ Second, all communities had to be located within a single geographic region experiencing amenity-based population and economic growth. This criterion was established in an attempt to control for potential regional variations in the availability of potential informational sources (i.e., the number of local newspapers, civic groups, etc.). The third and distinguishing criterion was that the set of communities had to vary in their population sizes and associated population densities. This third criterion, coupled with the fact the analytical methods used were literally replicated within each case, allowed me to make comparative inference across the study communities regarding the potential relationship between population and informational network densities (Yin 2009).

\section{Community Selection and Description}

Following the three selection criteria outlined above, I selected three small cities (Waynesville, Franklin, and Spruce Pine) located within extreme western North Carolina, USA. The region has a long history of natural resource dependence, primarily within the forestry and mining industries (Salstrom 1997). However, in recent decades the natural resource-based industries have steadily declined and been supplanted my amenity-oriented growth and development (Case et al. 2008; Kirk et al. 2012; Shultz 2011). The three cities of Waynesville, Franklin, and Spruce Pine vary substantially in their population size and densities (Table 1). The largest city of Waynesville had a 2010 population of 9,869 and a density of about 489 people $/ \mathrm{km}^{2}$ while the smallest city of Spruce Pine had a 2010 population of only 2,175 and a more sparse density of about 215 people $/ \mathrm{km}^{2}$. Also note that all three cities have experienced population growth, and concurrent increases in population densities, since 2000. Both Waynesville and Spruce Pine have also been experiencing population growth since at least 1990.

\section{Secondary Data Collection}

The first method used in my examination of these three communities involved drawing upon secondary data sources to determine whether or not there was a relationship between changes in population density and the transition away from natural resource based industries and toward amenity based industries. In short, I wanted to establish a clear link between amenity-led growth and changes in the spatial densities of each population. I accomplished this by compiling secondary data on employment in natural resource based industries

\footnotetext{
${ }^{4}$ I defined economic dependence as having at least $10 \%$ employment in natural resource based industries (farming, forestry, fishing, hunting, and mining) at one point in time from 1970 to 2010.
} 
Table 1 Populations, areas, and densities of study cities

\begin{tabular}{|c|c|c|c|c|c|c|}
\hline City & Population & $\begin{array}{l}10 \text {-year population } \\
\text { change }\end{array}$ & $\begin{array}{l}\text { Annual growth rate } \\
\text { for previous decade }\end{array}$ & $\begin{array}{l}\text { Area } \\
\left(\mathrm{km}^{2}\right)\end{array}$ & $\begin{array}{l}\text { Density } \\
\text { (pop./km²) }\end{array}$ & $\begin{array}{l}\text { 10-year } \\
\text { density change }\end{array}$ \\
\hline \multicolumn{7}{|c|}{ Waynesville, NC } \\
\hline 2010 & 9,869 & 637 & 0.67 & 20.2 & 488.56 & \multirow[t]{3}{*}{31.53} \\
\hline 2000 & 9,232 & 2474 & 3.17 & 20.2 & 457.03 & \\
\hline 1990 & 6,758 & & & 20.2 & & \\
\hline \multicolumn{7}{|c|}{ Franklin, NC } \\
\hline 2010 & 3,845 & 355 & 0.97 & 10.1 & 380.69 & \multirow[t]{3}{*}{35.15} \\
\hline 2000 & 3,490 & -588 & -1.54 & 10.1 & 345.54 & \\
\hline 1990 & 4,078 & & & 10.1 & & \\
\hline \multicolumn{7}{|c|}{ Spruce Pine, NC } \\
\hline 2010 & 2,175 & 145 & 0.69 & 10.1 & 215.35 & \multirow[t]{3}{*}{14.36} \\
\hline 2000 & 2,030 & 20 & 0.10 & 10.1 & 200.99 & \\
\hline 1990 & 2,010 & & & 10.1 & & \\
\hline
\end{tabular}

Data source: 2010, 2000, and 1990 US Censuses (www.census.gov)

a Annual growth rate $=\left(\left(\left(\frac{t_{n}}{t_{0}}\right)^{1 / 10}\right)-1\right) \times 100$. Where $t_{0}=$ original population and $t_{n}=$ population 10 years later

as well as amenity-based industries and analyzing its correlation with changes in population densities over time.

Note that this preliminary analysis draws upon data aggregated at the county level and is not exclusive to the three study communities that form the core focus of this research. The limited availability of census tract level data on employment by industry ${ }^{5}$ required me to make the trade-off between either just assuming each of these cities was transitioning toward and amenity-based economy, or using more gross levels of data to illustrate that, at least, the counties which contain these cities have experienced notable shifts in their social and economic composition over the past several decades.

\section{Natural Resource Dependence}

There are a variety of ways to gauge natural resource dependence; typically it involves either the proportion of a locality's total earned wages coming from natural resource related industries or the proportion of a locality's total number of jobs being within those industries (Stedman et al. 2007). In this research, I opt for the proportional employment approach, which has successfully been utilized in a variety of different contexts (Freudenburg and Gramling 1994; Nord 1994; Smith et al. 2012). Three county-level employment measures were compiled from the US Bureau of Economic Analysis (www.bea.gov). These measures

\footnotetext{
$\overline{5}$ This is especially true in small cities where potential sources of data are censored to avoid disclosure pertaining to a specific organizations or individuals (US Census Bureau 2012a).
}

were: Employment in farming; employment in agricultural services, forestry, fishing, and hunting; and employment in mining. I summed employment counts across the latter three measures and divided it by total employment in all industries to create the proportional employment in natural resource based industries measure.

\section{Amenity Dependence}

Like natural resource dependence, there are a variety of ways to measure amenity dependence. McGranahan (1999) suggest the environmental characteristics (e.g., topography, natural water bodies) of a city's surrounding landscape are good indicators. Johnson and Beale (2002) alternatively suggest a community's recreational infrastructure (e.g., per capita receipts from hotels/motels) serve as better measures. And still others (Winkler et al. 2012; Winkler 2010) suggest an alternative composite measure of seasonal home-ownership rates, proportion of the population that has recently in-migrated from metropolitan areas, and the proportion of housing units valued at more than $\$ 200,000$ US. While all of these measures are valuable, and suitable to specific research questions, they are all either relatively static in nature (e.g., an area's environmental conditions or recreational infrastructure change slowly over time) or they rely on secondary data that are only reported at large time intervals such as decennial Censuses (e.g., measures of owner-occupied housing rates). Consequently, they are not particularly suited to illustrating changes in amenity dependence over time.

In this study, I utilize a simple annual indicator, the proportion of an area's total employment in service-based 
industries, as an indirect measure of amenity transition. Similar approaches have been used elsewhere (Hoffman 2008) using the logic that increases in amenity migrants and second-home ownership will result in an increase in the need for service industry jobs (Power and Barrett 2001; Vias and Carruthers 2005; Winkler et al. 2007). I divided the employment count for services industries ${ }^{6}$ by a county's total employment in all industries to generate the proportional employment in services-based industries measure.

For both the natural resource and service sector dependence measures, data are annual from the year 1971 to 2007. For each industry, I matched the Standard Industrial Classification (SIC) codes (which were used to identify industries from 1969 to 2000) to the North American Industrial Classification System (NAICS) codes (which have been in use since 2001) to compile the most comprehensive dataset.

\section{Population}

The measures of population come from two sources. For the years 1980, 1990, and 2000 I used actual population counts for each city as reported by the decennial US Census. For intermediate years, I used the mid-year population estimates published by the US Census Bureau (2012b).

\section{Secondary Data Analysis}

Secondary data analysis simply involves calculation of a correlation matrix comprised of the proportion of natural resource employment, the proportion of employment in service related industries, and the population density for each county.

\section{Social Network Data Collection}

For a large proportion of social science research, the collection of network data is impractical. Records of relationships between individuals and organizations frequently do not exist, or if they do, they might not contain information about the characteristics of the relationship that are of interest. More commonly however, the social system for which the researcher would like to make inference to is too large or diverse to reliably collect data on all relevant relationships. Under these conditions, social scientists often utilize data

\footnotetext{
${ }^{6}$ Prior to 2001, the SIC system aggregates all service industry jobs. Since 2001, the newer NAICS codes separate service industry jobs into the following categories: arts, entertainment, and recreation related employment; employment in accommodation and food services; professional and technical employment; management jobs; employment in administration, waste, and remediation services; educational service related employment; and employment in health care services. I sum the counts across all these industries to match them with the pre-2001 SIC-based data.
}

generated from representative samples drawn from the system of interest (Freeman 2004). Data is collected on sampled individuals' relationships with other individuals, groups, or events (i.e., the data represent egocentric networks ${ }^{7}$ ) and, if the sample is representative of the population of interest, inference can be made about the characteristics of relationships within that population (Frank 2011; Marsden 2011).

If a researcher decides to use survey methods to collect network data, they must make several critical decisions prior to data collection. First, they must decide whether relationships of interest exist between a single set of units (e.g., individuals) or multiple sets (e.g., the relationships between individuals and groups). Is the network of interest one-mode or two-mode? Second, they must define the boundary of the population for which they want to draw inference (Laumann et al. 1989). Third and finally, they should define the types of ties, for which data can be collected, that are important for answering their research questions.

Regarding the first point, my research question is concerned with the aggregate characteristics of informational networks within a community. This includes both the flow of information between individual actors and the flow of information between individuals and organizations such as local religious, civic, and educational groups. Consequently, my research design called for soliciting information about ties between two sets of units, individuals and potential sources of information. The networks are two-mode.

To address the second point of solving the boundary specification problem, I chose to limit the populations of interest to all full-time homeowners residing within the city limits of the three study communities. Here, as in other research using survey samples to generate network data and inference about aggregate social groups (e.g., Marsden 1990), the boundary specification is relatively easy to solve given the "boundary" of the network coincides with the entire population residing within a given area.

The third and final point calls for addressing the types of ties within the network that are of interest. I chose not to measure and treat all informational ties equally. Rather, in concordance with the study's theoretical underpinnings, I wanted to gauge whether the information that was provided by a source was either trusted or distrusted.

\section{Survey Methodology}

I used surveys delivered and returned via mail to collect data on the informational networks within the three study cities of Waynesville, Franklin, and Spruce Pine. Within each city, I

\footnotetext{
$\overline{7}$ As opposed to representing "whole-networks" by collecting data for each relationship within a bounded social group, and which can be used to describe the structure of that group.
} 
drew random samples of 300 full-time resident homeowners from public tax records (i.e., 900 total homeowners sampled).

\section{Informational Sources and Trust}

The questionnaires, which I mailed in the summer of 2011, included a question that stated "...I would like to know where you obtain information about local community issues and how much you trust information from those sources." Respondents were then given a list of 13 potential informational sources to which they indicated whether they either "always trusted that source", "trusted the source only sometimes", or "always distrusted the source." Respondents were also given the option of indicating that they do not get information from that particular source. Initial analysis of this data involved treating it as two-mode individual-by-source network data and utilizing traditional social network analysis measures (Latapy et al. 2008).

\section{Social Network Data Analysis}

In the lexicon of social network analysis, the survey data collected involve two modes, individuals and informational sources, and thus can be analyzed as an affiliation network. The analysis of the structure of each community's informational network involves the calculation of node-level measures (density, degree centrality, closeness centrality, betweenness centrality, and eigenvector centrality) and graph (network) level measures (degree centralization, closeness centralization, and betweenness centralization) (Hanneman and Riddle 2011). All matrix manipulation was completed with $\mathrm{R}$ (www.rproject.org) and all network analysis was completed with the user written igraph package (www.igraph.sourceforge.net).

\section{Density}

Density is simply the number of ties present within a network (Borgatti and Everett 1997). Density values are typically normalized by dividing the total number of observed ties by the maximum number possible, which in this analysis is $2(n)(13)$. Density values near 0 would be expected in "loosely connected" networks whereas density values near 1 represent a "highly connected" network. Note that density values are computed prior to transforming the two-mode data to one-mode data of informational sources. ${ }^{8}$

\section{Centrality}

Degree Degree centrality is a count, calculated for each node, of the number of edges incident upon that node (Borgatti and

\footnotetext{
$\overline{{ }^{8} \text { The density }}$ value calculated from source-by-source matrix would undoubtedly be 1 given each unique pair of informational sources is likely to be used by at least one respondent.
}

Everett 1997). For my data, the degree centrality for each informational source simply refers to the number of sampled respondents who reported using that source. Given the data are generated from a representative sample of each city's population, degree centrality can also be normalized relative to sample size and expressed as the proportion of each sample who use each particular informational source.

Closeness Closeness centrality is a measure of how "far" an individual node is to all other nodes within the network. It is calculated for each node and is defined as the inverse of the average length of the shortest paths to/from all other nodes within a graph (Freeman 1979). For two-mode data, the raw centrality measure must be normalized to account for the fact that each node cannot be a geodesic distance of one from nodes of an alternative type (i.e., informational sources or individuals are not directly connected). This normalization involves dividing the raw closeness measure into $n_{j}+2\left(n_{i}-1\right)$ where $n_{i}$ is the number of nodes of a particular type (individuals) and $n_{j}$ is the number of nodes of the alternative type (informational sources).

Betweenness Betweenness, the third measure of centrality, is a sum of all the shortest paths between nodes that go through a given node. Here, betweenness centrality is calculated for each informational source and thus can be interpreted as the number of shortest paths between individuals which go through that particular source. Following Borgatti and Everett (1997), I normalize betweenness centrality measures to account for the two-mode nature of the data. Normalization involves dividing the raw betweenness centrality by

$$
\begin{aligned}
& \left(0.5 \times n_{1}\left(n_{i}-1\right)\right)+(0.5 \times(13-1)(13-2)) \\
& \quad+\left((13-1)\left(n_{i}-1\right)\right)
\end{aligned}
$$

where $n_{i}$ is the size of each sample.

Eigenvector The final measure of centrality I consider is eigenvector centrality, which is defined as the principal eigenvector of the adjacency matrix of a graph (Bonacich 1991). Eigenvector centrality assumes a node's centrality within the network is a function of the centrality of all other nodes connected to it. Here, the eigenvector centrality of each informational source is the sum of the centralities of all the individuals who use that source. I normalize the eigenvector centrality measure to account for the twomode nature of the data. This normalization involves dividing raw eigenvector scores by the square root of one half, the maximum score theoretically obtainable for any single node in a two-mode graph (Borgatti and Everett 1997). 


\section{Centralization}

The next analysis of information network structure determined the extent to which each network has a central informational source that individuals utilize, its centralization (Freeman 1979). Centralization measures are simply graph (network) level measures based upon the centrality scores of each node within the network. Consequently, there are three network centralization measures (degree centralization, closeness centralization, and betweenness centralization) based upon the calculation of each type of centrality. Broadly, these measures express the degree of variance in a network as a percentage of the hypothetical perfectly centralized network (i.e., a star) of the same size. Centralization measures near 0 represent no variability across all nodes' centrality measures while measures near 1 represent a high degree of variability. Each centralization measure is normalized following the formula provided by Borgatti and Everett (1997).

\section{Informational Overlap}

After analyzing network level centralization measures I felt it prudent to examine the coverage overlap between informational sources (i.e., the number of individuals who use any unique pair of sources). This analysis serves a similar function as the centralization measures in that it illustrates the concentration of information provision among pairs of sources. The analysis of informational overlap involved converting the individual-by-source survey data into a source-by-source affiliation matrix (Borgatti and Everett 1997). When data on relationships of interest are not available, analysts can infer the presence and strength of those unobserved relationships if data are available on shared "affiliations" between that unit of analysis. In short, co-affiliations between units of interest can be used as indicators of unobserved ties (Borgatti and Halgin 2011). This study is concerned with the structure of informational networks (i.e., the relationships between different sources of information within a community). However, data collection on the relational nature of informational sources is highly difficult to collect. ${ }^{9}$ Alternatively, the data

\footnotetext{
${ }^{9}$ It would also require the analyst to make arbitrary distinctions as to what is and is not a potential informational source. For example, should only formal entities such as civic and religious groups be analyzed even though a vast majority of information flows through interpersonal connections? The approach adopted in this paper circumvents this limitation by simultaneously analyzing formal and informal sources of information. While the large majority of affiliation network studies evaluate individuals' membership in formal groups such as clubs (e.g., McPherson and Smith-Lovin 1986, 1987), a substantial literature also focuses on less well-bounded patterns of co-affiliation such as participation in online forums or message boards (e.g., Allatta 2003). As Feld (1981:1017) notes "the nature of relations to objects vary; yet they are abstractly similar in that they may be considered relations to generally defined foci; and they therefore have similar implications for group structure."
}

collected from a representative sample of individuals who use those informational sources can be drawn upon and operationalized as a proxy measure for the relative similarity between informational sources.

More formally, the two-mode individual-by-source matrix $\boldsymbol{A}$ is transformed into a one-mode source-by-source matrix $\boldsymbol{B}$ by multiplying it by its transpose $(\boldsymbol{B}=\boldsymbol{A} \boldsymbol{A})$. The source-by-source matrix simply represents the count of individuals within each sample who use each distinct pair of informational sources. After creating the one-mode matrices for each study community, I normalize the data to account for different sample sizes. This is accomplished simply by dividing the count value for each pair of informational sources, $b_{11}, b_{12}, \ldots, b_{m n}$, by the maximum count possible $(n){ }^{10}$ The subsequent matrix $\boldsymbol{B}^{*}$ is a non-binary matrix representing the similarity, or overlap, between each pair of informational sources. The analysis culminated by illustrating the density of informational overlap among pairs of informational sources. ${ }^{11}$

\section{Probability of Always Distrusting or Trusting Informational Sources}

All of the network analysis thus far has been based off of individuals' use of information, irrespective of individuals' personal appraisals of that information. The final stage in the analysis involved calculating the probability that individuals will either "always distrust" or "always trust" the information they indicate using. I accomplish this by comparing the whole two-mode informational network (used in previous analyses) with the two-mode networks comprised of only those informational sources that are "always distrusted" or "always trusted." I accomplish this by generating the reduced two-mode networks, matching individual respondents to the two-mode whole information network, and multiplying the resulting matrices by the transpose of the two-mode whole information network. ${ }^{12}$ The result is a 1 -mode sourceby-source matrix characterizing the number of individuals who either "always trusted" or "always distrusted" each unique pair of informational sources used. After normalizing this matrix (dividing by the diagonal of the 1-mode whole information network matrix), the result is a transition probability matrix characterizing the probability that individuals will either always distrust or trust each unique pair of informational sources used. This analysis culminates by illustrating

\footnotetext{
${ }^{10}$ I make the assumption that all informational sources are available to all respondents.

${ }^{11}$ While this one-mode matrix can subsequently be analyzed using typical network analytic techniques (so long as they don't require binary data), I felt it would be unfruitful given the relatively small number of potential informational sources.

${ }^{12}$ This process is identical to analysis of network mobility where affiliational membership is compared across years.
} 
the density of the probabilities among pairs of informational sources.

\section{Results}

Amenity-led Population Growth

First, I investigated the relationships between population growth and either declines in natural resource dependence or increases in amenity-based activities. The longitudinal data sets for population levels and employment in both natural resource and amenity-based industries are shown in Fig. 1. Three notable trends appear in the figure. First, all three counties have experienced steady and dramatic increases in population (and concurrently population densities) from 1971 to 2007 . Second, all three counties have experienced steady, if not notable, declines in natural resource based employment. Natural resource employment in Macon County, for example, dropped from a high of nearly $10 \%$ in the mid 1970 s to being nearly nonexistent in 2007. Finally, service industry employment appears to be positively related to population growth; this would be expected given the previous literature on the changing nature of economic activity in amenity transition communities.

Next, I calculate the correlation matrices for the three variables of interest; these matrices are shown in Table 2. The results confirm the three visual trends seen in Fig. 1. First, for two of the three counties (Haywood and Macon) there was a highly significant and negative relationship between the proportions of natural resource related employment and local population densities. For the third county (Mitchell) the relationship was negative, however not statistically significant. Second, for all three counties a significant and positive relationship was seen in the proportion of service based jobs and local population densities. Across the board, the level of correlation was very high (.8793-.9651). Finally, I noticed a negative relationship between the proportion of natural resource based jobs and the proportion of jobs in the service industry for two out of the three counties (Haywood and Macon)

Collectively, these results illustrate that all three counties are, or have, transitioned from a natural resource based economy to a service based economy as the data show steady declines in natural resource related jobs and dramatic increases in the types of employment most frequently associated with amenity-based communities. Furthermore, and more importantly, these results illustrate that amenity transition implies not just dramatic shifts in the dominant modes of economic activity, but shifts in local population densities as well. These preliminary findings suggest amenity transition communities might be undergoing some fundamental social changes related to how their residents interact and communicate with one another. The next stage of the analysis explicitly tests this
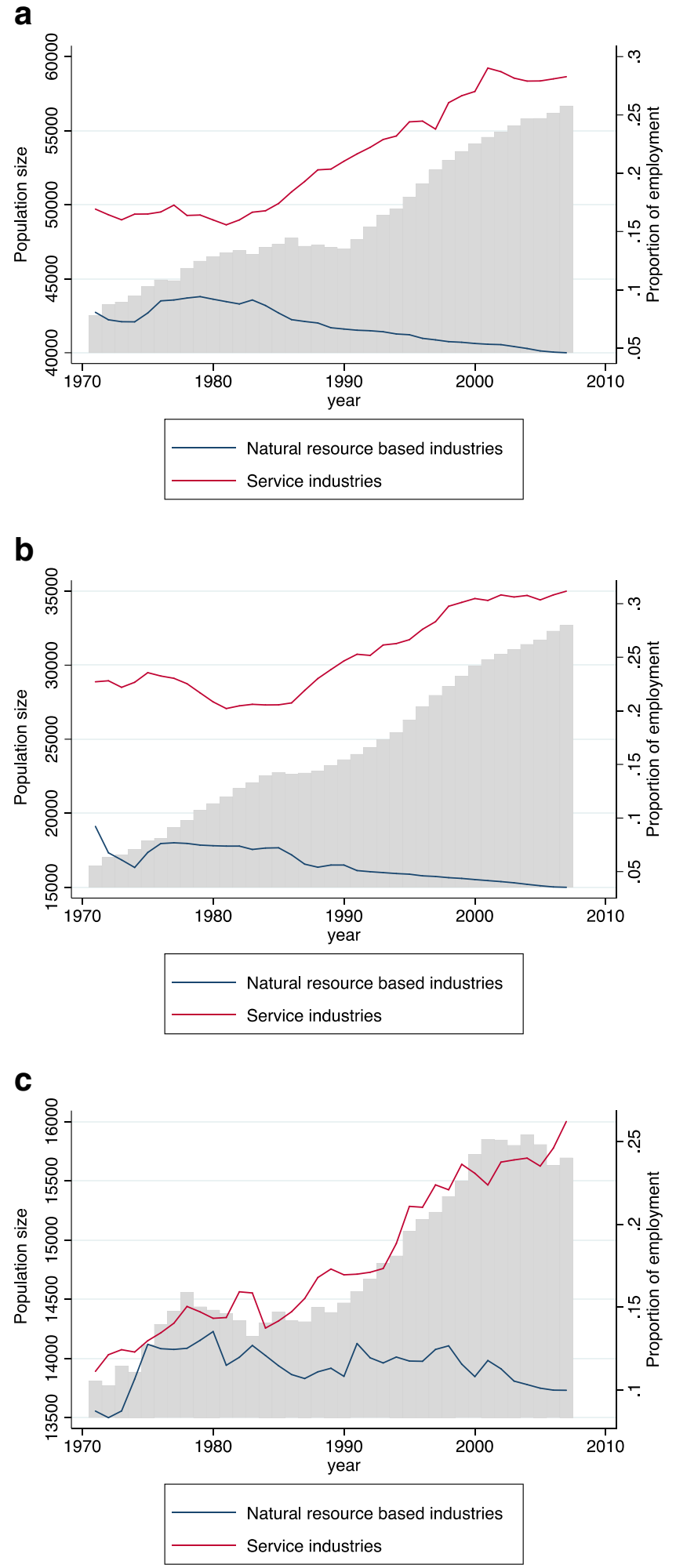

Fig. 1 Changes in population size and amenity-related industries in three study communities a Haywood County (Waynesville), North Carolina b Macon County (Franklin), North Carolina c Mitchell County (Spruce Pine), North Carolina

proposition by looking at variations in community information networks across the three study communities. 
Table 2 Correlation matrices for each county

$* * * p \leq 0.001$

\begin{tabular}{|c|c|c|}
\hline \multicolumn{3}{|l|}{ Haywood County, NC (Waynesville) } \\
\hline & Population density & $\begin{array}{l}\text { Proportion of natural resource } \\
\text { related employment }\end{array}$ \\
\hline Proportion of natural resource related employment & $-0.8416^{* * *}$ & \\
\hline Proportion of employment in service industries & $0.9472 * * *$ & $-0.9340 * * *$ \\
\hline \multicolumn{3}{|l|}{ Macon County, NC (Franklin) } \\
\hline & Population density & $\begin{array}{l}\text { Proportion of natural resource } \\
\text { related employment }\end{array}$ \\
\hline Proportion of natural resource related employment & $-0.8740 * * *$ & \\
\hline Proportion of employment in service industries & $0.8793 * * *$ & $-0.8740 * * *$ \\
\hline \multicolumn{3}{|l|}{ Mitchell County, NC (Spruce Pine) } \\
\hline & Population density & $\begin{array}{l}\text { Proportion of natural resource } \\
\text { related employment }\end{array}$ \\
\hline Proportion of natural resource related employment & -0.0094 & \\
\hline Proportion of employment in service industries & $0.9651^{* * *}$ & -0.0539 \\
\hline
\end{tabular}

\section{Community Characteristics}

Of the 900 mailed questionnaires, 40 were undeliverable because the potential respondent no longer resided at the address reported in the property tax records, or because they had died since the records were updated. For the remaining delivered questionnaires, 420 were returned and completed; this tabulates out to a $48.8 \%$ response rate.

I began the analysis with an initial comparison of the samples' sociodemographic characteristics (Table 3). For all three samples, respondents tended to be near middle age and predominantly male (as would be expected surveying individuals listed on property tax records). On average, respondents in Waynesville and Franklin reported household incomes of between $\$ 50,000$ and $\$ 75,000$ per year; income levels were slightly less ( $\$ 35,000$ to $\$ 50,000$ per year) in Spruce Pine. Respondents were also predominantly white. Across all the sociodemographic characteristics queried about, the samples' data were not significantly different when compared to 2010 Census data on owner-occupied housing units.

\section{Aggregate Measures of Informational Use}

Across all three study communities, respondents indicated using just over half of the 13 informational sources asked about (Waynesville: $M=7.16, S D=3.32$; Franklin: $M=6.67$, $S D=3.77$; Spruce Pine: $M=7.10, S D=3.80)$. However, the data reveal a large amount of variability in the extent of trust that individuals place in each potential informational source (Fig. 2). By and large, residents in each of the three communities tend to trust the information they receive from immediate family members, churches, close friends, and local newspapers more than information coming from other sources. The least trusted information, again across all three study communities, comes from elected officials, national television news, online news sources, and coworkers.

Table 3 Sociodemographic characteristics of each study community

\begin{tabular}{llll}
\hline & $\begin{array}{l}\text { Waynesville, NC } \\
n=159\end{array}$ & $\begin{array}{l}\text { Franklin, NC } \\
n=158\end{array}$ & $\begin{array}{l}\text { Spruce Pine, NC } \\
n=103\end{array}$ \\
\hline Median age $^{\mathrm{a}}$ & 53 & 55 & 51 \\
Percent female $^{2}$ & 31 & 32 & 26 \\
Modal household income category $^{\mathrm{b}}$ & $\$ 50,000-\$ 74,999$ & $\$ 50,000-\$ 74,999$ & $\$ 35,000-\$ 75,000$ \\
Percent white $^{\mathrm{c}}$ & 99 & 96 & 97 \\
\hline
\end{tabular}

${ }^{a}$ Not significantly different than 2010 Census data on owner-occupied housing units (Waynesville, $\chi^{2}(p)=0.092$; Franklin, $\chi^{2}(p)=0.076$; Spruce Pine, $\left.\chi^{2}(p)=0.051\right)$

${ }^{\mathrm{b}}$ Not different than 2010 Census data on owner-occupied housing units

${ }^{\mathrm{c}}$ Not significantly different than 2010 Census data on owner-occupied housing units (Waynesville, $t(10053)=0.333, p>.05$; Franklin, $t(4001)=$ $0.116, p>.05$; Spruce Pine, $t(2276)=0.124, p>.05$ 
Fig. 2 Trust in different informational sources by study community a Waynesville, North Carolina b Franklin, North Carolina c Spruce Pine, North Carolina

\section{a}

Immediate family members

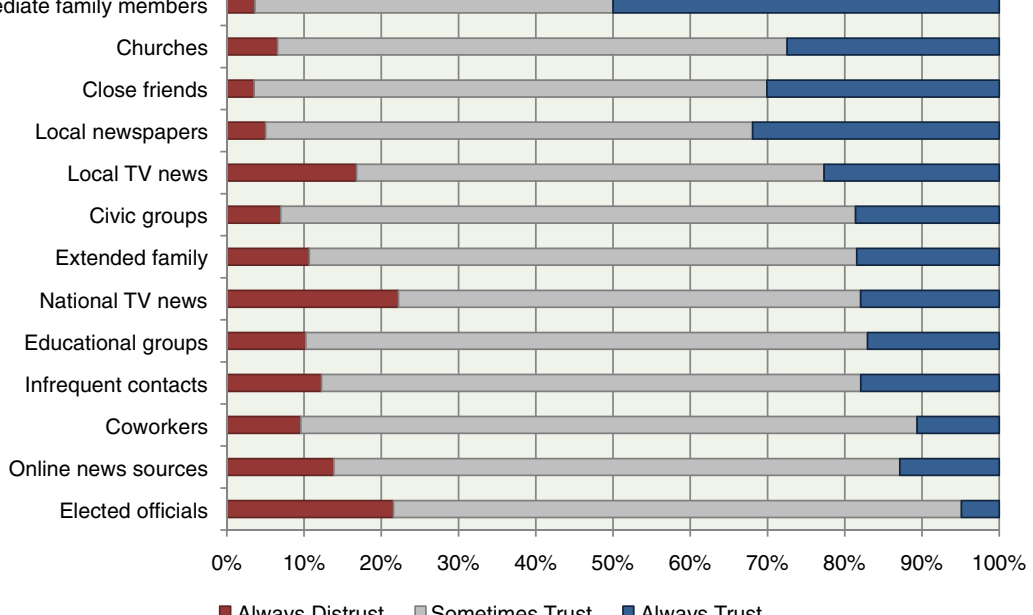

b

Immediate family members

Churches

Close friends

Local newspapers

Local TV news

Civic groups

Extended family

National TV news

Educational groups

Infrequent contacts

Coworkers

Online news sources

Elected officials

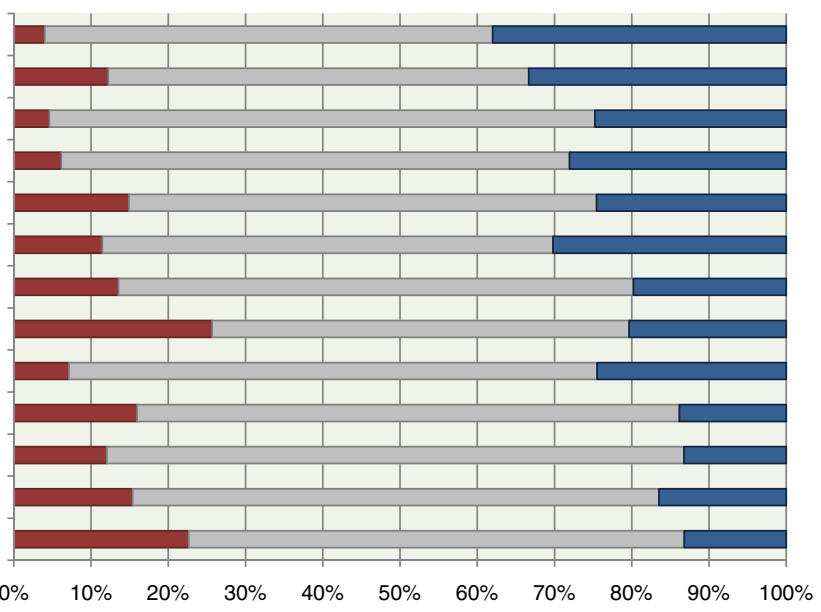

$\square$ Always Distrust $\square$ Sometimes Trust $\square$ Always Trust

\section{C}

Immediate family members

Churches

Close friends

Local newspapers

Local TV news

Civic groups

Extended family

National TV news

Educational groups

Infrequent contacts

Coworkers

Online news sources

Elected officials

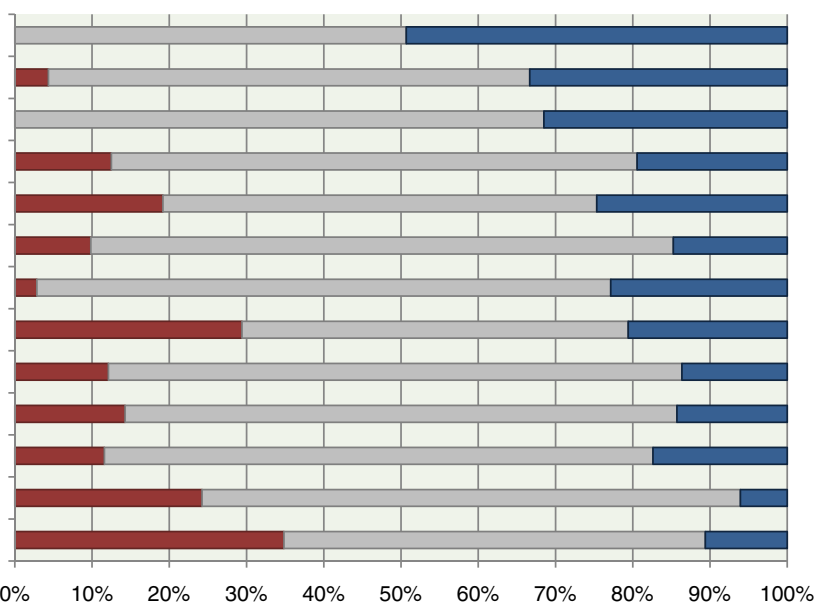

घ Always Distrust $\square$ Sometimes Trust $\square$ Always Trust 
Fig. 3 Informational network of each sample. Randomly sampled individuals are shown as small grey circles and potential sources of community information is represented by larger circles a Waynesville, NC b Franklin, NC c Spruce Pine, N
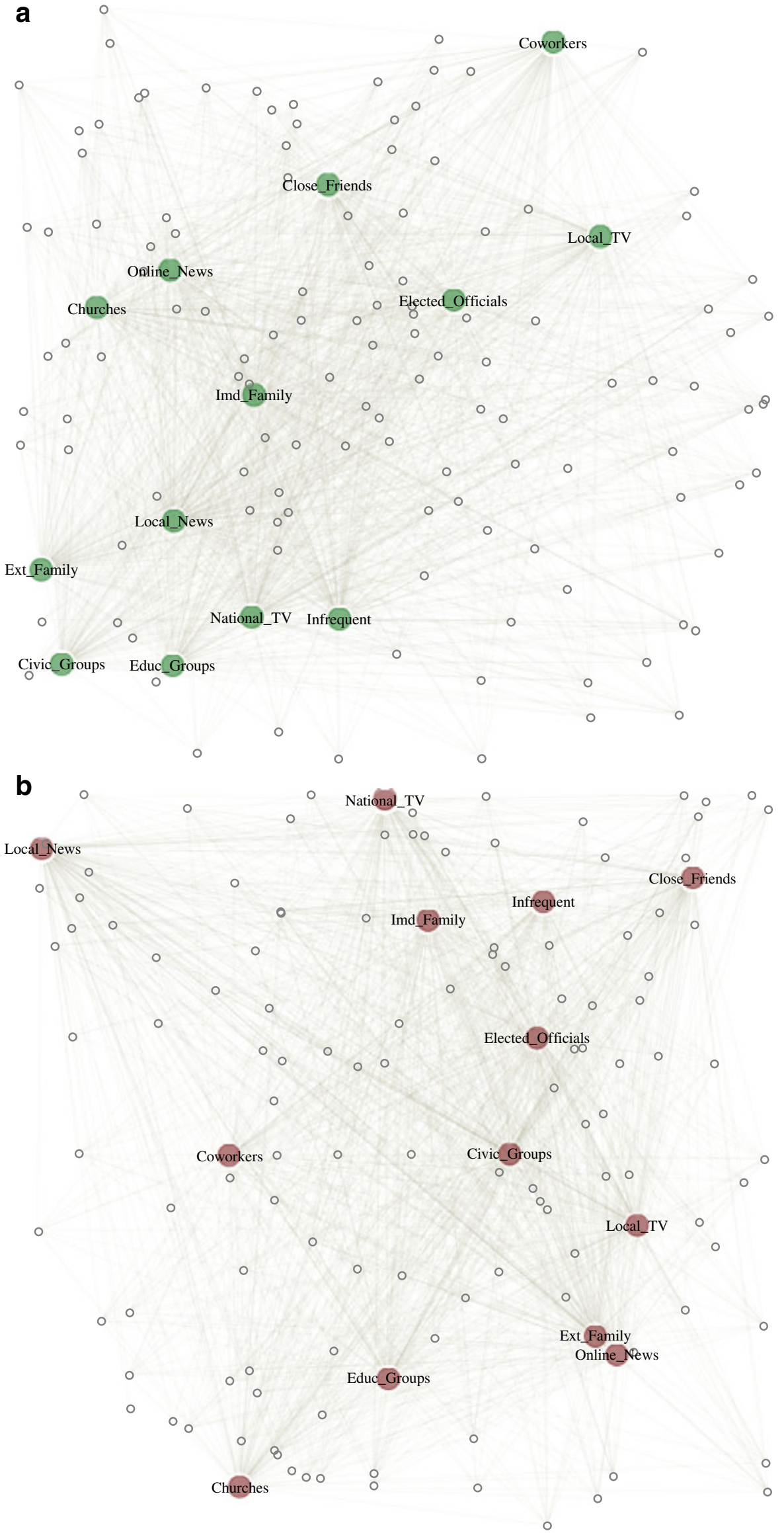
Fig. 3 (continued)

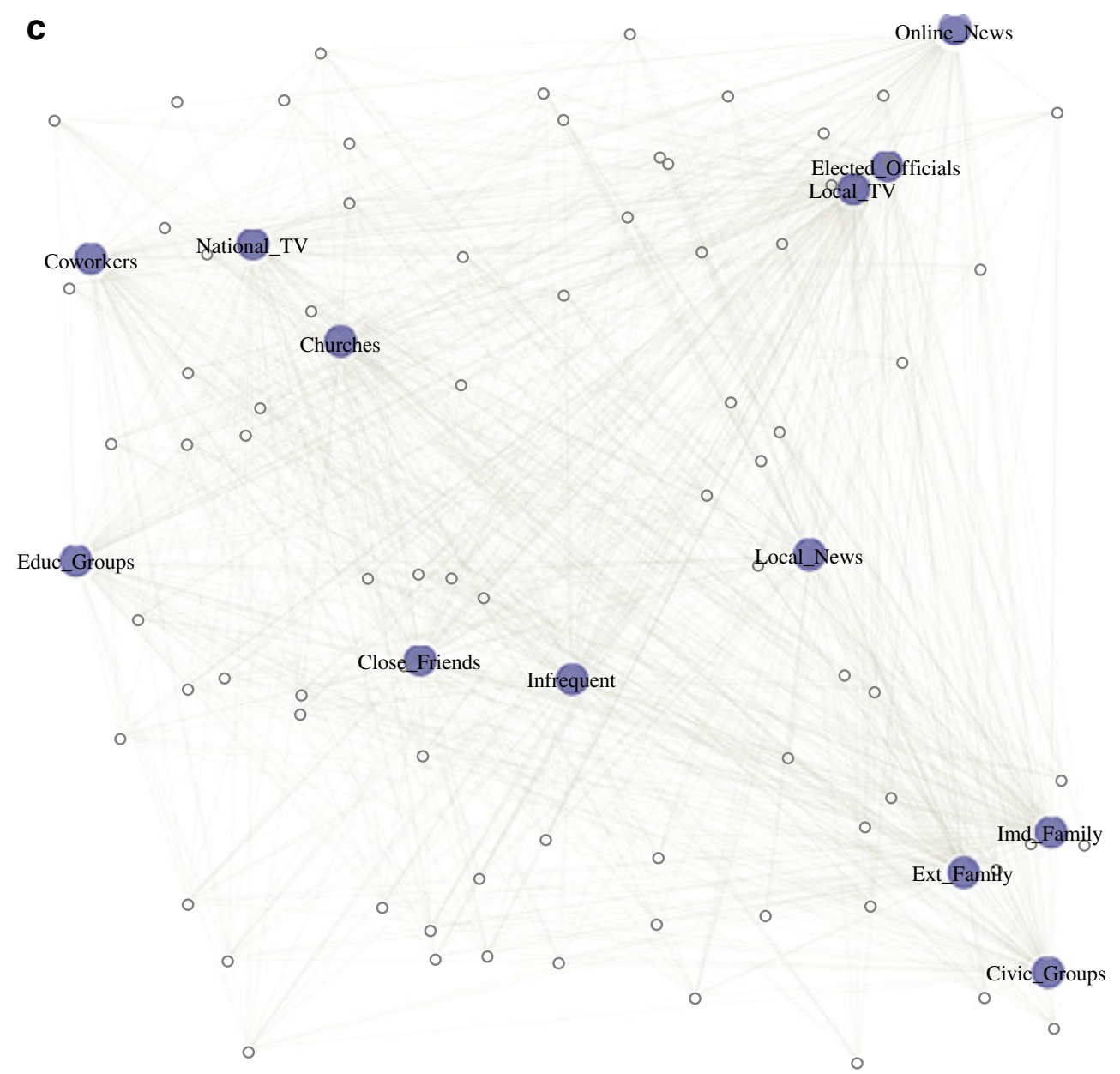

\section{Social Network Measures}

\section{Density and Centrality}

The network analysis began with the two-mode individualsource datasets. The informational networks of each city are illustrated in Fig. 3, Panels A, B, and C. Analysis of each network's density, normalized for different sample sizes, yielded roughly similar values (Waynesville $=0.3263$; Franklin $=0.3174$; Spruce Pine $=0.3346$ ). Concurrently, I noticed little variation in the use of individual informational sources across the three study communities as shown by the degree centrality measures reported in Table 4 . These findings were expected, as past empirical work suggests network density is not monotonically related to population density. These findings, while suggesting that patterns of information exchange are similar across all three sample communities, do not speak to the relational structure of information networks. This stems from the fact that simple density measures of bipartite networks are aggregate counts of the edges (connections) within a network divided by the total potential number of edges.
To better discern how informational sources are related to one another, I turned my attention to the three additional measures of centrality. All three centrality measures, closeness centrality, betweenness centrality, and eigenvector centrality, did not reveal a monotonic pattern across the three communities (Table 4). ${ }^{13}$ These initial results provide support for the hypothesis that the centrality of informational sources does not fluctuate relative to population density.

\section{Centralization}

Moving beyond the centrality scores of individual informational sources, I estimated graph (network) level centralization measures; this was done to explicitly address the proposition that informational networks in less populous areas are less centralized (i.e., individuals use more diverse set of informational sources to find information about issues that affect their

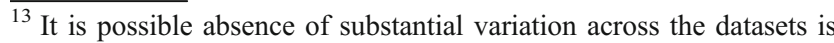
attributable, at least in part, to the simple bipartite nature of the data. More revealing variations might be seen if whole-network data were available within each community.
} 
Table 4 Centrality measures for each sample's complete informational network

\begin{tabular}{|c|c|c|c|c|c|c|c|c|c|c|c|c|}
\hline & \multicolumn{3}{|c|}{ Normalized Degree } & \multicolumn{3}{|c|}{ Normalized Closeness } & \multicolumn{3}{|c|}{ Normalized Betweenness } & \multicolumn{3}{|c|}{$\begin{array}{l}\text { Normalized Eigenvector } \\
\text { Centrality }\end{array}$} \\
\hline & Waynesville & Franklin & $\begin{array}{l}\text { Spruce } \\
\text { Pine }\end{array}$ & Waynesville & Franklin & $\begin{array}{l}\text { Spruce } \\
\text { Pine }\end{array}$ & Waynesville & Franklin & $\begin{array}{l}\text { Spruce } \\
\text { Pine }\end{array}$ & Waynesville & Franklin & $\begin{array}{l}\text { Spruce } \\
\text { Pine }\end{array}$ \\
\hline Local News & 0.75 & 0.72 & 0.70 & 0.42 & 0.39 & 0.37 & 0.062 & 0.068 & 0.039 & 0.304 & 0.296 & 0.288 \\
\hline Close Friends & 0.71 & 0.69 & 0.71 & 0.41 & 0.38 & 0.37 & 0.053 & 0.049 & 0.054 & 0.295 & 0.293 & 0.283 \\
\hline $\begin{array}{l}\text { Infrequent } \\
\text { Contacts }\end{array}$ & 0.67 & 0.60 & 0.68 & 0.40 & 0.38 & 0.37 & 0.044 & 0.029 & 0.041 & 0.282 & 0.267 & 0.278 \\
\hline Coworkers & 0.59 & 0.53 & 0.67 & 0.38 & 0.37 & 0.37 & 0.029 & 0.021 & 0.039 & 0.258 & 0.240 & 0.276 \\
\hline $\begin{array}{l}\text { Immediate } \\
\text { Family }\end{array}$ & 0.69 & 0.63 & 0.71 & 0.40 & 0.38 & 0.37 & 0.047 & 0.034 & 0.044 & 0.291 & 0.281 & 0.288 \\
\hline $\begin{array}{l}\text { Extended } \\
\text { Family }\end{array}$ & 0.65 & 0.61 & 0.68 & 0.39 & 0.38 & 0.37 & 0.036 & 0.031 & 0.039 & 0.280 & 0.271 & 0.278 \\
\hline Local TV & 0.75 & 0.72 & 0.71 & 0.42 & 0.39 & 0.37 & 0.062 & 0.057 & 0.044 & 0.304 & 0.300 & 0.289 \\
\hline National TV & 0.74 & 0.72 & 0.66 & 0.42 & 0.39 & 0.36 & 0.058 & 0.055 & 0.033 & 0.302 & 0.300 & 0.276 \\
\hline Civic Groups & 0.54 & 0.61 & 0.59 & 0.36 & 0.38 & 0.35 & 0.024 & 0.031 & 0.024 & 0.239 & 0.272 & 0.254 \\
\hline $\begin{array}{l}\text { Educational } \\
\text { Groups }\end{array}$ & 0.55 & 0.62 & 0.64 & 0.37 & 0.38 & 0.36 & 0.025 & 0.033 & 0.030 & 0.246 & 0.275 & 0.271 \\
\hline $\begin{array}{l}\text { Elected } \\
\text { Officials }\end{array}$ & 0.64 & 0.67 & 0.64 & 0.39 & 0.38 & 0.36 & 0.038 & 0.043 & 0.029 & 0.273 & 0.290 & 0.273 \\
\hline Churches & 0.57 & 0.57 & 0.67 & 0.37 & 0.38 & 0.37 & 0.028 & 0.025 & 0.034 & 0.250 & 0.259 & 0.280 \\
\hline $\begin{array}{l}\text { Online News } \\
\text { Sources }\end{array}$ & 0.64 & 0.58 & 0.64 & 0.39 & 0.38 & 0.36 & 0.038 & 0.031 & 0.030 & 0.269 & 0.254 & 0.270 \\
\hline
\end{tabular}

community.) The centralization measures (Table 5) do not provide definitive support for this hypothesis, as observed differences in normalized centralization measures were marginal.

\section{Information Overlap}

After generating the information overlap matrices I plotted the density of overlap measures (Fig. 4). The illustration provides a direct measure of the number of informational sources that overlap in their coverage of city residents. The plot clearly illustrates two divergent patterns, one for Spruce Pine and one for both Waynesville and Franklin. There is noticeably more overlap across informational sources in the most rural city of Spruce Pine relative to the other two cities. The peak in the plot corresponding to Spruce Pine suggests 10 of the 13 informational sources queried about are all used by around 92 to $93 \%$ of the population. Similar to the analysis of the

Table 5 Centralization measures

\begin{tabular}{llll}
\hline & Waynesville, NC & Franklin, NC & Spruce Pine, NC \\
\hline Degree & 0.513 & 0.492 & 0.439 \\
Closeness & 0.461 & 0.429 & 0.332 \\
Betweenness & 0.054 & 0.049 & 0.048 \\
\hline
\end{tabular}

centralization measures, this finding does not provide definitive support for the hypothesis that informational networks in

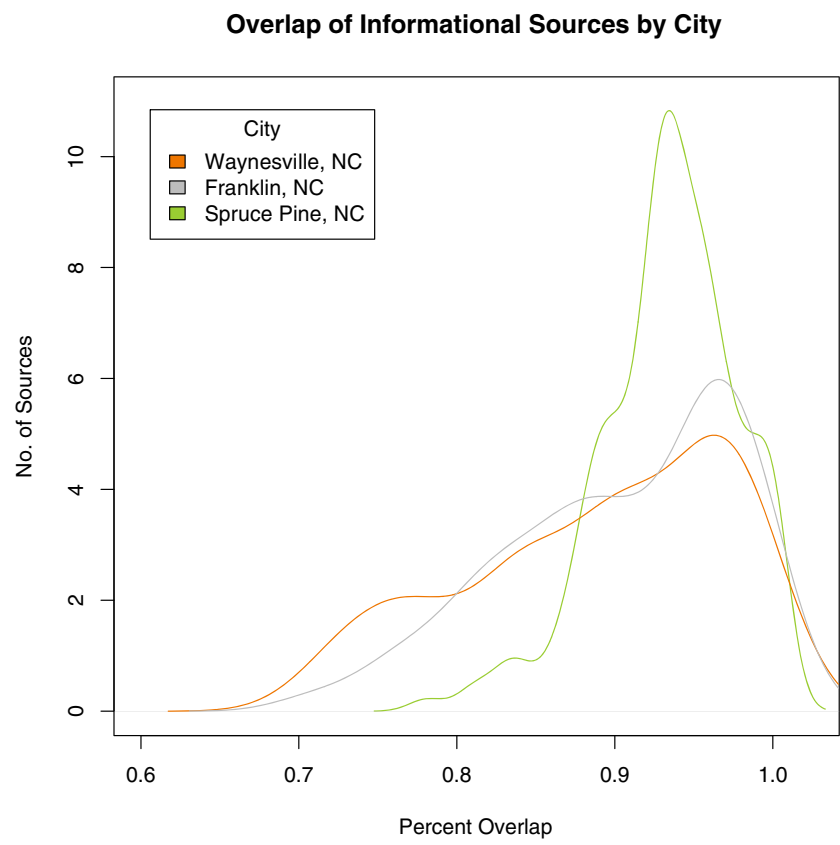

Fig. 4 Informational network density of study communities. The yaxis (density) is a count of informational sources within each community. The $\mathrm{x}$-axis (overlap) represents the proportion of the population who use that number of informational sources 
less populous areas are less centralized as the observed density of source overlap was not monotonically related to population density. Support for rejecting the hypothesis would have required more substantial variation between the cities of Franklin and Waynesville.

\section{Probability of Always Distrusting or Trusting Informational Sources}

The final stage of the analysis focused on the qualitative nature of information use. I created both a reduced "always trusting" and "always distrusting" network and compared it against the whole two-mode informational network generated within each city to generate two separate transition probability matrices. I plotted the density of these matrices to most succinctly illustrate the findings. Fig. 5 illustrates the probability of individuals "always trusting" informational sources if they are used. Across all three communities, no substantial variation appears evident. On average, there is between 10 to $15 \%$ chance that about five of the informational sources will always be trusted if they are used. Also, there appears to be about a 45 to $50 \%$ chance that at least one source is always be trusted. The fact that there is no substantial variation across the three cities suggests I should reject the second hypothesis that the probability of always trusting information would be higher in more rural areas.

Figure 6 illustrates the probability of individuals "always distrusting" informational sources if they are used. Here, I noticed a unique differentiation between the communities.

Probability of 'Always Trusting' Informational Sources by City

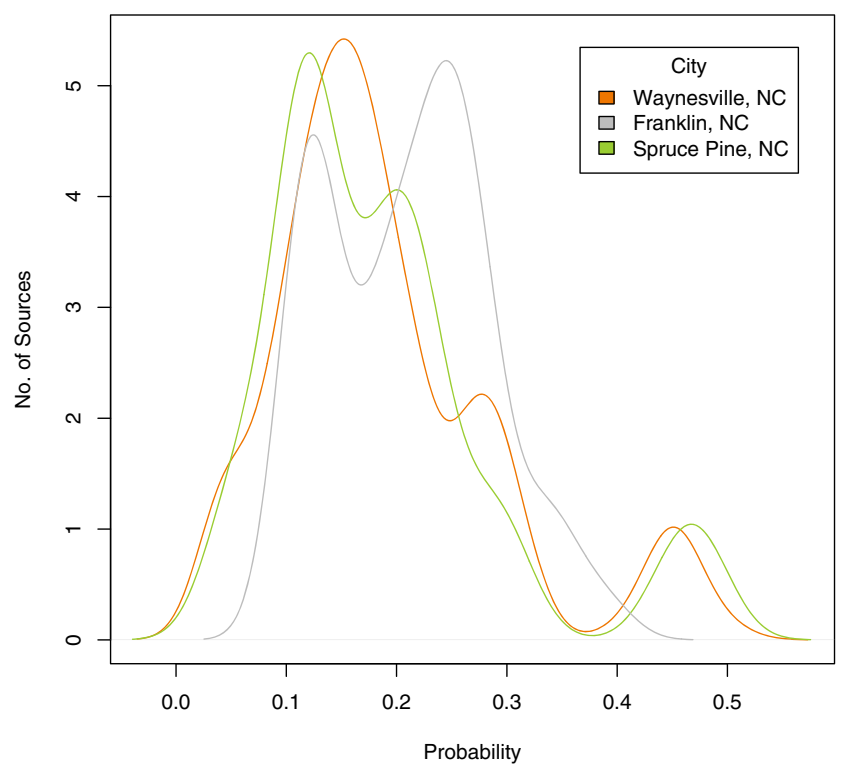

Fig. 5 Predicted probabilities of always trusting informational sources. The y-axis (density) is a count of informational sources within each community. The $\mathrm{x}$-axis (probability) is the predicted probability of individuals always distrusting or trusting an informational source if they use it

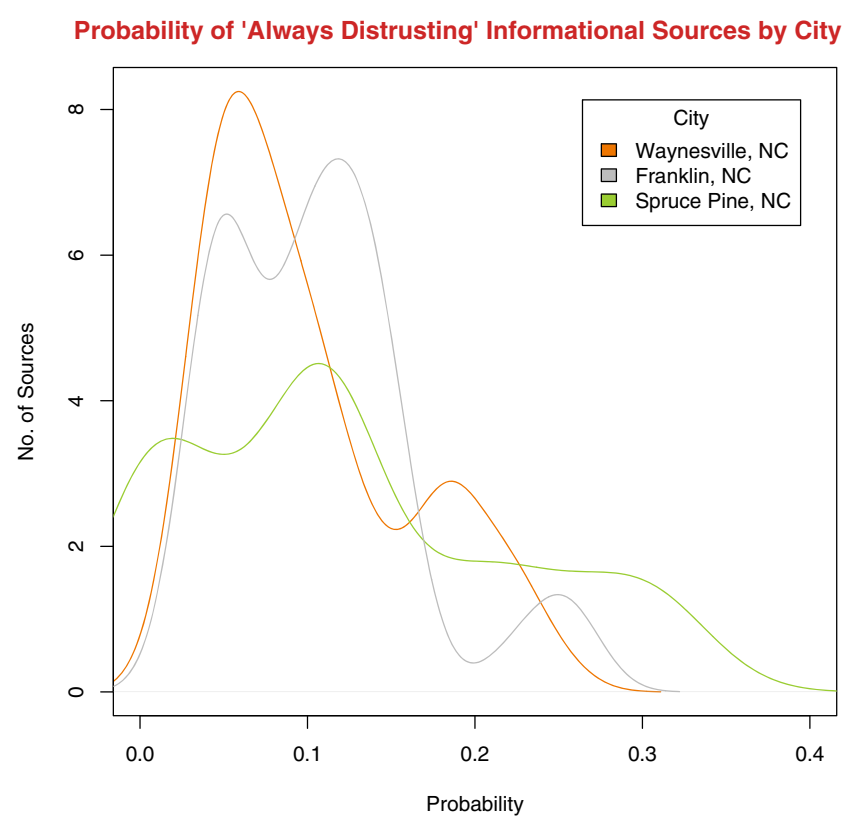

Fig. 6 Predicted probabilities of always distrusting informational sources. The y-axis (density) is a count of informational sources within each community. The $\mathrm{x}$-axis (probability) is the predicted probability of individuals always distrusting or trusting an informational source if they use it

There is a greater probability of distrusting a relatively few number of informational sources in the smallest community of Spruce Pine, as can be seen in the heavy right-hand tail of the density plot. Conversely, for both Franklin and Waynesville, the data reveal a much smaller probability of always distrusting sources of information. However, that distrust is more widespread among informational sources. On average, there is between 5 and $15 \%$ chance of individuals in either of these communities always distrusting the information they receive from about six different sources. Finding variation in the probability of distrusting informational sources across all three cities suggests I should not readily reject the hypothesis that the probability of always distrusting information would be higher in more urban areas. Rather, it illustrates that distrust may just be more acute and focused among a select few informational sources in smaller communities like Spruce Pine.

The raw data collected on whether individual sources of information were always trusted or distrusted can be used to further illustrate this point. I observed several expected monotonical trends (Figs. 7 and 8). Namely, individuals in the Spruce Pine were more likely to "always distrust" information received from local news sources, infrequent contacts, coworkers, national television, elected officials, and online news sources relative to their more urban counterparts. ${ }^{14}$

\footnotetext{
${ }^{14}$ Pearson $\chi^{2}$ tests across the three study communities revealed the observed frequency of individuals either distrusting, sometimes trusting, or always trusting each source of information was not significantly different than expected frequencies $\left(d f=4, \chi^{2} \leq 9.390, p \geq 0.052\right)$.
} 


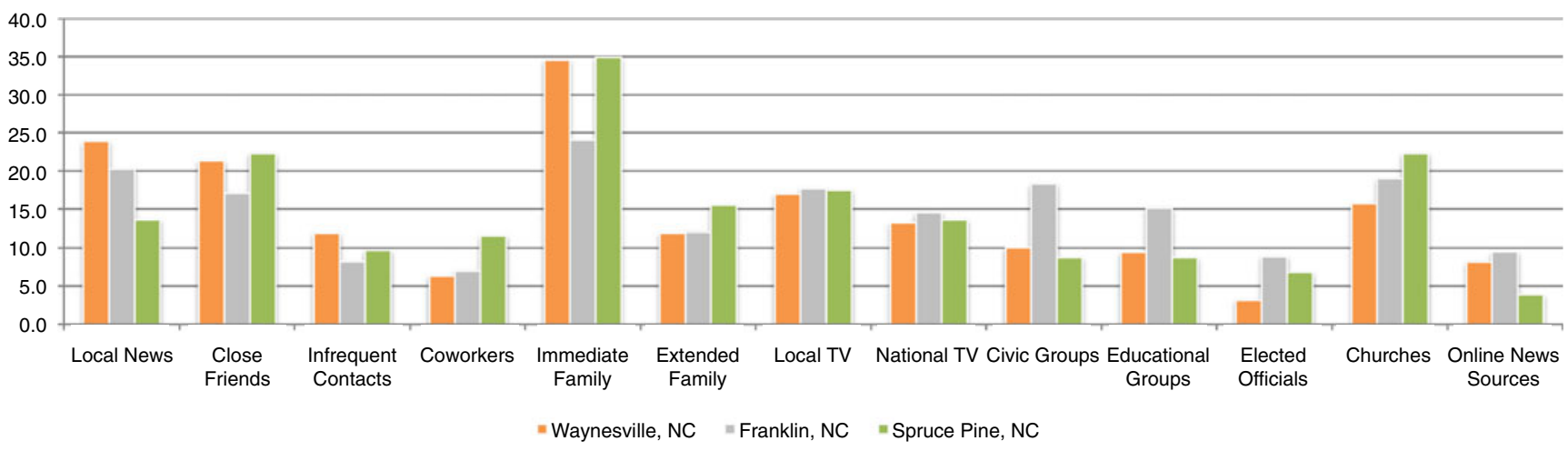

Fig. 7 Proportion of respondents by city indicating they "always trust" the information from a given source

\section{Discussion}

Through this study, I examined whether a decreased concentration in informational density and a decreased level of trust placed in others and social institutions were related to variations in the population densities of three amenity transition communities. I formed two hypotheses based upon sociological theory and previous empirical findings.

The first hypothesis was formulated by drawing upon Toennies' conceptualization of community structures that transition from gemeinschaft to gesellschaft as populations aggregate and form more urban settlement patterns. Previous empirical research to explicitly examine Toennies' "lineardevelopment" hypothesis has not found any evidence for a relationship between the macro-level community characteristic of population density and the micro-level characteristics of individuals' interpersonal relationships (Kasarda and Janowitz 1974; Sampson 1988). Consequently, I hypothesized similar empirical evidence would be yielded from the analysis of network data collected from three communities arranged on a population density continuum. The data support this hypothesis. Namely, I found little variation in the use of informational sources across the three study communities as shown by the four different measures of centrality and the three different centralization measures. I also did not find a relationship between population density and the concentration, or overlap, of information dissemination. Informational overlap in the most rural community of Spruce Pine was clearly different than the other two communities. However, a consistent and monotonical relationship, as would be expected under the linear-development hypothesis, was not found. Taken collectively, results from the network analysis support previous empirical work.

The analyses also expound upon previous findings, namely those of Kasarda and Janowitz (1974) and Sampson (1988), by extending them beyond measures of kinship and friendship ties to less intimate extended networks and affiliations. Previously, only theoretical conjectures could be made about the presence of these "weak" ties in less-populated areas. Specifically, (Wilkinson 1991) notes that less-densely populated communities are at a structural disadvantage because the probability of individuals interacting with others is lower relative to dense urban areas. The analyses of network data, however, do not support this proposition. It appears that

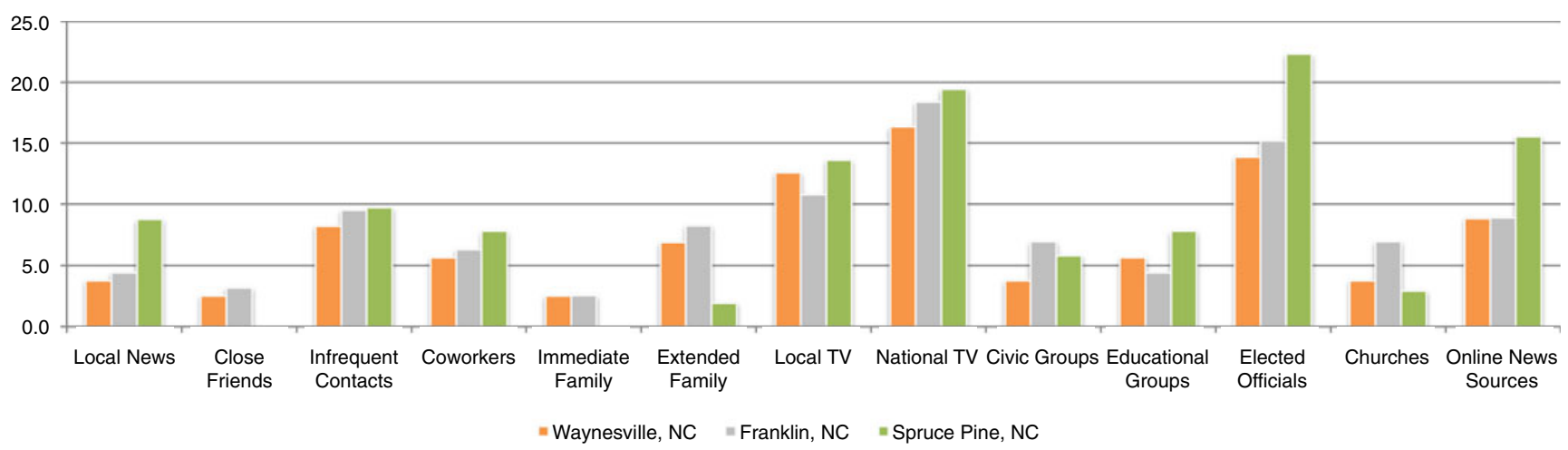

Fig. 8 Proportion of respondents by city indicating they "always distrust" the information from a given source 
individuals' information seeking behavior among both close kinship/ties and extended/affiliational ties is independent of the macro-structural characteristic of population density.

The second hypothesis I formulated focused on the qualitative nature of informational exchange, namely the level of trust that individuals placed in various informational sources. Previous empirical evidence (Beggs et al. 1996; Hofferth and Iceland 1998; Lee et al. 1994) tends to support the proposition that relational networks in more sparsely populated areas are characterized by higher degrees of trust in others and in organizations. Consequently, I hypothesized the network data would yield similar results. The results, however, yielded little support for this hypothesis. These unexpected results illustrate some previously unexamined nuances of the relationship between informational networks and population densities. Specifically, the analysis revealed relatively little variation in the concentration (overlap) of always trusted informational sources relative to the variable densities that define each community. This finding suggests a rejection the second hypothesis, under which it would be assumed that trust was higher among the more rural informational networks. The analysis also revealed notable variation in the concentration (overlap) of always distrusted informational sources. The informational network of Spruce Pine exhibited the greatest concentrations of distrust, followed by the less populous cities of Franklin and Waynesville (Fig. 6). Previous empirical research would predict the informational networks of more urban areas to have higher levels of distrust; these data suggest that this is not the case. I can generate more inference by looking at which relational ties are characterized by distrust (Fig. 8). Local news sources, infrequent contacts, coworkers, national television, and elected officials were all more distrusted in the less densely populated communities. These are all non-intimate contacts/affiliations that are most frequently classified as "weak" ties. No variation is seen among the "strong" ties (i.e., close friends and immediate family members). So while I reject the proposition of a relationship between the trust/distrust placed in micro-level interpersonal ties and the macro-level community characteristic of a population, I add the important caveat that the placement of trust/distrust in individual ties is likely to depend upon whether those ties are to immediate family and friends or whether they are to extended contacts and institutions.

\section{Implications}

This study originated from a question of whether amenity transition, which has become a dominant social demographic pattern in amenity rich communities over the past several decades, was accompanied by changes in the composition of the informational networks utilized by individuals within those communities. Previous research has documented the social consequences of amenity in-migration well. Most notably, conflict arises between long-term residents, who tend to be more concerned with "their" community, and incoming residents, who are more transitory and less vested in the community affairs. However, amenity in-migration also leads to shifts in population densities, which as long-standing sociological theory would suggest, also might have consequences on how individuals within those communities interact. Theory predicts that information exchange in amenity transition communities is likely to become more decentralized as populations aggregate and become organized in more dense settlement patterns. Theory would also predict that informational networks would become characterized by more distrust as urbanization occurs. Consequently, environmental and community planners would not only face the burden of developing plans and conducting operations amidst conflicting social values (i.e., long-timers versus newcomers), they would also face the social structural burdens of more diffuse and distrusting informational networks.

The network data collected among the three sample communities, however, suggest that the likelihood of these social structural barriers to accompany amenity transition is low. ${ }^{15}$ By this, I am not implying that amenity transition is a process absent of social tension and distrust. Rather, I simply imply that the conflicts associated with amenity transition are more likely to arise because of conflicting value systems and ideologies as opposed to social structural changes in the communities themselves. The road ahead for environmental and community planners in amenity transition communities is likely to be difficult, but the data from this study suggest that it is not likely to be due to changes in macro-social community characteristics, particularly changing population densities.

\section{References}

Allatta, J. T. (2003). Structural analysis of communities of practice: An investigation of job title, location, and management intention. In Huysman, M., Wenger, E., and Wulf, V. (eds.), Communities and Technologies. Kluwer, Amsterdam, pp. 23-42.

Beaudoin, C. E., and Thorson, E. (2004). Social capital in rural and urban communities: Testing differences in media effects and models. Journalism \& Mass Communication Quarterly 81(2): 378-399 doi:10.1177/107769900408100210.

Beggs, J. J., Haines, V. A., and Hurlbert, J. S. (1996). Revisiting the ruralurban contrast: Personal networks in nonmetropolitan and metropolitan settings. Rural Sociology 61(2): 306-325 doi:10.1111/ j.1549-0831.1996.tb00622.x.

Bell, M. (1992). The fruit of difference: The rural-urban continuum as a system of identity. Rural Sociology 57(1): 65-82.

Bonacich, P. (1991). Simultaneous group and individual centralities. Social Networks 13(2): 155-168 doi:10.1016/0378-8733(91)90018-O.

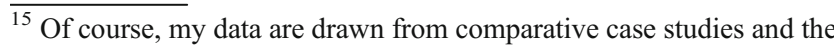
findings cannot be generalized to all communities undergoing some form of community transition.
} 
Borgatti, S. P., and Everett, M. G. (1997). Network analysis of 2-mode data. Social Networks 19(3): 243-269 doi:10.1016/S0378-8733(96)00301-2.

Borgatti, S. P., and Halgin, D. S. (2011). Analyzing affiliation networks. In Scott, J., and Carrington, P. J. (eds.), The SAGE handbook of social network analysis. Sage, London, pp. 417-433.

Brint, S. (2001). Gemeinschaft revisited: A critique and reconstruction of the community concept. Sociological Theory 19(1): 1-23.

Brunson, M., Shindler, B., and Steel, B. S. (1997). Consensus and dissension among rural and urban publics concerning forest management in the Pacific Northwest. In Public lands management in the west. Praeger, Westport.

Case, D., Fowler, D., Morgan, H., Schwellenbach, S., and Culbertson, K. (2008). Moving to the mountains: Amenity migration in the Sierra and Southern Appalachian mountains. In Wescoat, J. L., and Johnston, D. M. (eds.), Political economies of landscape change. Springer, Netherlands, pp. 77-88.

Coleman, J. S. (1990). Relations of trust. In Foundations of social theory. Harvard University Press, Cambridge, MA, pp. 91-116.

Durkheim, E. (1933). The division of labor in society. (G. Simpson, Trans.). Free Press, Glencoe, IL.

England, L., and Brown, R. B. (2003). Community and resource extraction in rural America. In Brown, D. L., and Swanson, L. E. (eds.), Challenges for rural America in the twenty-first century. The Pennsylvania State University Press, University Park, PA, pp. 317-328.

Entwisle, B., Faust, K., Rindfuss, R. R., and Kaneda, T. (2007). Networks and contexts: Variations in the structure of social ties. American Journal of Sociology 112(5): 1495-1533.

Feld, S. L. (1981). The focused organization of social ties. American Journal of Sociology 86(5): 1015-1035.

Field, D. R., Luloff, A. E., and Krannich, R. S. (2002). Revisiting the origins of and distinctions between natural resource sociology and environmental sociology. Society \& Natural Resources 15(3): 213-227 doi:10.1080/089419202753445052.

Flora, C. B., and Flora, J. L. (2008). Rural communities: Legacy and change, 3rd ed. Westview, Boulder, CO.

Frank, O. (2011). Survey sampling in networks. In Scott, J. P., and Carrington, P. (eds.), The SAGE handbook of social network analysis. Sage, London, pp. 389-403.

Freeman, L. (2001). The effects of sprawl on neighborhood social ties: An explanatory analysis. Journal of the American Planning Association 67(1): 69-77 doi:10.1080/01944360108976356.

Freeman, L. C. (1979). Centrality in social networks: I. Conceptual clarification. Social Networks 1: 215-239 doi:10.1016/03788733(78)90021-7.

Freeman, L. C. (2004). The development of social network analysis: A study in the sociology of science. Empirical Press, Vancouver, British Columbia.

Freudenburg, W. R. (1992). Addictive economies: Extractive industries and vulnerable localities in a changing world economy. Rural Sociology 57(3): 305-332 doi:10.1111/j.1549-0831.1992.tb00467.x.

Freudenburg, W. R., and Gramling, R. (1994). Natural resources and rural poverty: A closer look. Society \& Natural Resources 7: 5-22 doi:10.1080/08941929409380841.

Gosnell, H., and Abrams, J. (2011). Amenity migration: Diverse conceptualizations of drivers, socioeconomic dimensions, and emerging challenges. GeoJournal 76(4): 303-322 doi:10.1007/s10708009-9295-4.

Granovetter, M. S. (1973). The strength of weak ties. American Journal of Sociology 78(6): 1360-1380.

Greider, T., Krannich, R. S., and Berry, E. H. (1991). Local identity, solidarity, and trust in changing rural communities. Sociological Focus 24(4): 263-282 doi:10.1080/00380237.1991.10570594.

Hanneman, R. A., and Riddle, M. (2011). Concepts and measures for basic network analysis. In The SAGE handbook of social network analysis. Sage, Los Angeles, pp. 340-369.
Hofferth, S. L., and Iceland, J. (1998). Social capital in rural and urban communities. Rural Sociology 63(4): 574-598 doi:10.1111/ j.1549-0831.1998.tb00693.x.

Hoffman, S. L. (2008). Application of resiliency theory and adaptive cycles as a framework for evaluating change in amenity-transition communities (Unpublished master's thesis). Utah State University.

Holmes, J. (2002). Diversity and change in Australia's rangelands: A post-productivist transition with a difference? Transactions of the Institute of British Geographers 27(3): 362-384 doi:10.1111/ 1475-5661.00059.

Holmes, J. (2006). Impulses towards a multifunctional transition in rural Australia: Gaps in the research agenda. Journal of Rural Studies 22(2): 142-160 doi:10.1016/j.jrurstud.2005.08.006.

Hurley, P., and Walker, P. (2004). Whose vision? Conspiracy theory and land-use planning in Nevada County, California. Environment and Planning A 36(9): 1529-1547 doi:10.1068/a36186.

Jacobs, J. (1961). The death and life of great American cities. Random House, New York.

Johnson, K. M. (1999). The rural rebound. Population Reference Bureau, Washington, DC

Johnson, K. M., and Beale, C. L. (2002). Nonmetro recreation counties: Their identification and rapid growth. Rural America 17: 12-19.

Kasarda, J. D., and Janowitz, M. (1974). Community attachment in mass society. American Sociological Review 39(3): 328-339.

Kirk, R. W., Bolstad, P. V., and Manson, S. M. (2012). Spatio-temporal trend analysis of long-term development patterns (1900-2030) in a Southern Appalachian county. Landscape and Urban Planning 104(1): 47-58 doi:10.1016/j.landurbplan.2011.09.008.

Latapy, M., Magnien, C., and Del Vecchio, N. (2008). Basic notions for the analysis of large two-mode networks. Social Networks 30: 31 48 doi:10.1016/j.socnet.2007.04.006.

Laumann, E. O., Marsden, P. V., and Prensky, D. (1989). The boundary specification problem in network analysis. In Linton C. Freeman, D. R. White, \& A. K. Romney (Eds.), Research methods in social network analysis (pp. 61-87). George Mason University Press, Fairfax, VA.

Lee, G. R., Coward, R. T., and Netzer, J. K. (1994). Residential differences in filial responsibility expectations among older persons. Rural Sociology 59(1): 100-109 doi:10.1111/j.1549-0831.1994.tb00524.x.

Maier, K. (2001). Citizen participation in planning: Climbing a ladder? European Planning Studies 9(6): 707-719 doi:10.1080/713666506.

Marsden, P. V. (1987). Core discussion networks of Americans. American Sociological Review 52: 122-131.

Marsden, P. V. (1990). Network data and measurement. Annual Review of Sociology 16: 435-463.

Marsden, P. V. (2011). Survey methods for network data. In Scott, J. P., and Carrington, P. (eds.), The SAGE handbook of social network analysis. Sage, Los Angeles, pp. 370-388.

McGranahan, D. A. (1999). Natural amenities drive rural population change (Agricultural Economic Report No. 781). USDA Economic Research Service, Food and Rural Economics Division, Washington, DC. p. 24.

McPherson, J. M., and Smith-Lovin, L. (1986). Sex segregation in voluntary associations. American Sociological Review 51(1): 61-79.

McPherson, J. M., and Smith-Lovin, L. (1987). Homophily in voluntary organizations: Status distance and the competition of face-to-face groups. American Sociological Review 52(3): 370-379.

Nelson, P. B. (2001). Rural restructuring in the American West: Land use, family and class discourses. Journal of Rural Studies 17(4): 395-407 doi:10.1016/S0743-0167(01)00002-X.

Nord, M. (1994). Natural resources and persistent rural poverty: In search of the nexus. Society \& Natural Resources 7: 205-220 doi:10.1080/08941929409380860.

Pahl, R. E. (1966). The rural-urban continuum. Sociologia Ruralis 6(3): 299-329 doi:10.1111/j.1467-9523.1966.tb00537.x. 
Power, T. M., and Barrett, R. N. (2001). Post-cowboy economics: Pay and prosperity in the new American west. Island Press, Washington, DC.

Putnam, R. D. (1993). Making democracy work: Civic traditions in modern Italy. Princeton University Press, Princeton, NJ.

Salamon, S. (2003a). Newcomers to old towns: Suburbanization of the heartland. University of Chicago, Chicago, IL.

Salamon, S. (2003b). From hometown to nontown: Rural community effects of suburbanization. Rural Sociology 68(1): 1-24 doi:10.1111/ j.1549-0831.2003.tb00126.x.

Salstrom, P. (1997). Appalachia's path to dependency: Rethinking a region's economic history, 1730-1940. The University Press of Kentucky.

Sampson, R. J. (1988). Local friendship ties and community attachment in mass society: A multilevel systemic model. American Sociological Review 53(5): 766-779 doi:10.2307/2095822.

Sanders, I. T., and Lewis, G. F. (1976). Rural community studies in the United States: A decade in review. Annual Review of Sociology 2: 35-53 doi:10.1146/annurev.so.02.080176.000343.

Saraceno, E. (1994). Alternative readings of spatial differentiation: The rural versus the local economy approach in Italy. European Review of Agricultural Economics 21(3-4): 451-474 doi:10.1093/erae/ $21.3-4.451$

Shultz, B. J. (2011). Emerging patterns of growth and change in the southeast. Southeastern Geographer 51(4): 550-563 doi:10.1353/ sgo.2011.0042.

Simmel, G. (1955). Conflict and the web of group affiliations. Free Press, Glencoe, IL.

Smith, J. W., Moore, R. L., Anderson, D. H., and Siderelis, C. (2012). Community resilience in Southern Appalachia: A theoretical framework and three case studies. Human Ecology 40: 341-353 doi:10.1007/s10745-012-9470-y.

Smith, M. D., Krannich, R. S., and Hunter, L. M. (2001). Growth, decline, stability, and disruption: A longitudinal analysis of social well-being in four western rural communities. Rural Sociology 66(3): 425-450 doi:10.1111/j.1549-0831.2001.tb00075.x.

Sorokin, P. A. (1979). Preface. In Toennies, F. (ed.), Community and Society. Harper, New York, pp. ix-X.

Stedman, R., White, W., Patriquin, M., and Watson, D. (2007). Measuring community forest-sector dependence: Does method matter? Society \& Natural Resources 20(7): 629-646 doi:10.1080/08941920701329660.
Toennies, F. (1887). Community and society-Gemeinschaft and Gesellschaft. (C. P. Loomis, Trans.). Michigan State University Press, East Lansing, MI.

Travis, W. R. (2007). New geographies of the American west: Land use and the changing patterns of place. Island Press, Washington, DC.

US Census Bureau. (2012a). USA Counties. Database. Retrieved September 3, 2012, from http://censtats.census.gov/usa/usa.shtml

US Census Bureau, D. I. D. (2012b). Population Estimates. Retrieved September 4, 2012, from http://www.census.gov/popest/estimates.html

Vias, A. C., and Carruthers, J. I. (2005). Regional development and land use change in the Rocky Mountain West, 1982-1997. Growth and Change 36(4): 244-272 doi:10.1111/j.1468-2257.2005.00276.x.

White, H. C., Boorman, S. A., and Breiger, R. L. (1976). Social structure from multiple networks. American Journal of Sociology 81: 730-780.

Wilkinson, K. P. (1991). The community in rural America. Greenwood Press, Westport, CT.

Wilson, G. A. (2001). From productivism to post-productivism.... and back again? Exploring the (un)changed natural and mental landscapes of European agriculture. Transactions of the Institute of British Geographers 26(1): 77-102.

Wilson, G. A. (2006). Multifunctional agriculture: A transition theory perspective. CABI, Cambridge, MA.

Winkler, R. L. (2010). Rural destinations, uneven development, and social exclusion (Unpublished doctoral dissertation). University of Wisconsin - Madison, Madison, WI.

Winkler, R. L., Cheng, C., \& Golding, S. (2012). Boom or bust? Population dynamics in natural resource-dependent counties. In L. J. Kulcsar \& K. J. Curtis (Eds.), International handbook of rural demography (pp. 349-367). Springer. Retrieved from 10.1007/ 978-94-007-1842-5 24

Winkler, R. L., Field, D. R., Luloff, A. E., Krannich, R. S., and Williams, T. (2007). Social landscapes of the inter-mountain west: A comparison of "old west" and "new west" communities. Rural Sociology 72(3): 478-501 doi:10.1526/003601107781799281.

Woods, M. (2003). Rural geography: Processes, responses, and experiences in rural restructuring. Sage, London.

Yin, R. K. (2009). Case study research: Design and methods (4th ed., Vol. 5). Sage, Los Angeles. 